\title{
Recent developments of acupuncture in Australia and the way forward
}

\author{
Charlie Changli Xue*, Anthony Lin Zhang, Angela Weihong Yang, \\ Claire Shuiqing Zhang and David Frederick Story
}

Address: World Health Organisation Collaborating Centre for Traditional Medicine, Discipline of Chinese Medicine, School of Health Sciences, RMIT University, Bundoora, Victoria 3083, Australia

Email: Charlie Changli Xue* - charlie.xue@rmit.edu.au; Anthony Lin Zhang - tony.zhang@rmit.edu.au; Angela Weihong Yang - angela.yang@rmit.edu.au; Claire Shuiqing Zhang - claire.zhang@rmit.edu.au; David Frederick Story - david.story@rmit.edu.au

* Corresponding author

Published: 29 April 2009

Chinese Medicine 2009, 4:7 doi:10.1 186/1749-8546-4-7

This article is available from: http://www.cmjournal.org/content/4/I/7

(C) 2009 Xue et al; licensee BioMed Central Ltd.

This is an Open Access article distributed under the terms of the Creative Commons Attribution License (http://creativecommons.org/licenses/by/2.0), which permits unrestricted use, distribution, and reproduction in any medium, provided the original work is properly cited.
Received: 13 August 2008

Accepted: 29 April 2009

\begin{abstract}
Almost one in ten Australians has received acupuncture treatment by acupuncturists and/or medical doctors in private clinics. The majority of Australian health insurance funds offer rebates for acupuncture. Statutory regulations for acupuncture have been implemented in the State of Victoria, Australia. Six acupuncture degree courses have been approved by the Chinese Medicine Registration Board of Victoria and/or accredited by the Australian Acupuncture and Chinese Medicine Association. Furthermore, a number of clinical trials of acupuncture on allergic rhinitis, pain and women's health were carried out in Australia. Recent developments of acupuncture in Australia indicate that through adequate and appropriate evaluation, acupuncture begins to integrate into mainstream health care in Australia.
\end{abstract}

\section{Background}

The history of acupuncture in Australia can be traced back to the 1850s when the first Chinese immigrants arrived and worked in the gold fields of Australia [1]. Acupuncture is now considered by the general public as one of the most popular treatments of complementary and alternative medicine (CAM) [2].

There have been four developmental stages of acupuncture in Australia. (1) Self-management stage (1850s1960s): Acupuncture was a form of unregulated health care. (2) Professional development stage (1970s-1980s): Acupuncture associations were established to promote the acupuncture profession and facilitate clinical practices.
(3) Standard-setting stage (1990s): Universities and private colleges started offering acupuncture training. Acupuncture became an established modality of CAM in Australia [3]. (4) Regulation stage (2000 onwards): The practice of acupuncture is subject to mandatory registration in the State of Victoria, Australia as stipulated by the Chinese Medicine Registration Act 2000 [4] which was superseded by the Health Professions Registration Act 2005 [5].

Here, we highlight the recent developments of acupuncture in terms of clinical practices, education, research and regulations in Australia and illustrate how acupuncture is being integrated into mainstream health care in Australia. 
Acupuncture users and practitioners in Australia In 2005, a national survey on 1,067 representative adults in Australia on the use of CAM revealed that nearly one in ten $(9.2 \%)$ Australians used acupuncture service over a 12-month period [2]. Australians made over ten million visits to acupuncturists every year. The study also concluded that acupuncture users were more likely to be born in Australia, having completed tertiary education, covered by private health insurance and living in the states of New South Wales, Victoria and Queensland [6].

Acupuncture can be provided by both acupuncturists and general medical practitioners with training in acupuncture. A 2004 survey on 636 medical practitioners showed that acupuncture was considered as one of the three most popular forms of CAM used by medical practitioners themselves [7]. Nearly one in five (18\%) general medical practitioners practiced acupuncture as part of their primary care and $76 \%$ of medical doctors referred their patients to acupuncturists at least once a month [7]. Over $70 \%$ of obstetricians and midwives considered acupuncture to be beneficial and safe to use during pregnancy according to another study on 220 obstetricians and midwives in Australia [8].

Over the past three decades, a number of Chinese medicine and acupuncture associations have been established in Australia, among which the Australian Acupuncture and Chinese Medicine Association (AACMA) is the largest one in Australia with over 1,400 members [9].

\section{Acupuncture education}

In Australia, private acupuncture colleges were first established in Sydney, Brisbane and Melbourne in the 1970s [9]. The Victoria University of Technology and the Royal Melbourne Institute of Technology (RMIT University) were among the first to offer degree courses in acupuncture and Chinese herbal medicine.

Twenty universities and colleges in Australia offer Chinese medicine courses at various levels which may also include acupuncture. Some of the acupuncture programs have been approved by the Chinese Medicine Registration Board of Victoria (CMRB) or recognised by the AACMA (Table 1). Moreover, the RMIT University, University of Technology Sydney and University of Western Sydney also offer research programs for acupuncture stream at postgraduate level. The State of Victoria has issued the Guidelines for the Approval of Courses of Study in Chinese Medicine as a Qualification for Registration [10].

A comparative study on the curricula and teaching quality between the RMIT University and Beijing University of Chinese Medicine was recently conducted [11]. While the curricula and educational objectives of the two programs were similar, differences existed in areas such as teaching classical Chinese medicine texts and clinical training in Chinese medicine hospitals. A survey on 228 registered Chinese medicine practitioners in Victoria was conducted in 2005 [12]. Its results showed that technical capabilities (acupuncture in particular) were considered as the most important in clinical practice, whereas research was considered the least important.

\section{Acupuncture regulation in Australia}

The Australian Government issued the Standards of Practice for Acupuncture - Health (Infectious Diseases) Regulations 1990 [13]. In 2000, the State of Victoria implemented the Chinese Medicine Registration Act [4] for the purpose of registration of Chinese medicine practitioners. This Act was subsequently replaced by the Health Professions Registration Act 2005 [5]. By April

Table I: List of acupuncture degree courses available in Australia

\begin{tabular}{lll}
\hline Course & Institution & Approving/Recognising bodies \\
\hline $\begin{array}{l}\text { Bachelor of Health Science (acupuncture): 4-year } \\
\text { undergraduate course }\end{array}$ & $\begin{array}{l}\text { Endeavour College of Natural Health (previously } \\
\text { Australian College of Natural Medicine), Queensland } \\
\text { and Victoria }\end{array}$ & CMRB*, AACMA \\
$\begin{array}{l}\text { Bachelor of Applied Science (Chinese medicine/ } \\
\text { human biology): 5-year undergraduate course }\end{array}$ & RMIT University, Victoria & CMRB, AACMA \\
$\begin{array}{l}\text { Master of Applied Science (acupuncture): 3-year } \\
\text { postgraduate course }\end{array}$ & RMIT University, Victoria & CMRB \\
$\begin{array}{l}\text { Bachelor of Health Science (Chinese medicine): 4- } \\
\text { year undergraduate course }\end{array}$ & Southern School of Natural Therapies, Victoria & CMRB*, AACMA* \\
$\begin{array}{l}\text { Bachelor of Health Science in traditional Chinese } \\
\text { medicine: 4-year undergraduate course }\end{array}$ & University of Technology Sydney, New South Wales & AACMA \\
$\begin{array}{l}\text { Bachelor of Applied Science (traditional Chinese } \\
\text { medicine): 4-year undergraduate course }\end{array}$ & University of Western Sydney, New South Wales & AACMA \\
\hline $\begin{array}{l}\text { Note: } \\
\begin{array}{l}\text { CMRB: Chinese Medicine Registration Board of Victoria } \\
\text { AACMA: Australian Acupuncture and Chinese Medicine Association }\end{array}\end{array}$ \\
$\begin{array}{l}\text { *Provisional approval/recognition } \\
\end{array}$
\end{tabular}


2009, the CMRB has registered 987 acupuncturists who met the requirements of the Act [14].

\section{Health insurance rebates for acupuncture}

At present, Australian national health insurance (i.e. Medicare) only covers the cost of acupuncture provided by registered medical practitioners. Between 2005 and 2006, the number of medical acupuncture visits rebated by Medicare was estimated to be 607,349 [15], representing less than $10 \%$ of the total estimated acupuncture visits per year [7]. Since the 1990s, most of the private health insurance companies in Australia, such as Medibank Private and Medical Benefits Fund of Australia, have been providing rebates for acupuncture.

\section{Research on acupuncture efficacy and safety} The RMIT Chinese Medicine Research Group (RCMRG) conducted randomised controlled trials (RCTs) on acupuncture as a treatment for allergic rhinitis, headache, migraine and chronic pain. An RCT involving 30 subjects [16] with seasonal allergic rhinitis showed a significant improvement after acupuncture treatment for nasal and non-nasal symptoms. Another RCT [17] involving persistent allergic rhinitis subjects $(n=80)$ showed that the symptom scores in the acupuncture group decreased significantly. These two RCTs suggest that acupuncture may be an effective and safe method to treat seasonal and persistent allergic rhinitis.

An RCT $(n=40)$ conducted by the RCMRG examined the efficacy of electroacupuncture for tension-type headache [18], concluding that electroacupuncture was effective for short-term symptomatic relief. In addition, a pilot RCT in a hospital in Victoria demonstrated that electroacupuncture had beneficial effects on short-term reduction of Opioid-like medication in subjects with chronic nonmalignant pain [19].

An RCT conducted at the University of Adelaide in South Australia involving 593 women with nausea and vomiting during early pregnancy suggested that acupuncture was generally safe for women of early pregnancy and that women receiving acupuncture had less nausea $(P<0.01)$ throughout the trial and less dry retching $(P<0.01)$ the second week onwards [20]. Another RCT on 228 patients found positive effects of acupuncture on clinical pregnancy rates for women undergoing embryo transfer [21].

Researchers in Australia have also made considerable contributions to the Cochrane Database of Systematic Reviews in the investigation on acupuncture to treat depression [22], induction of labour [23], lateral elbow pain [24], shoulder pain [25] and fibromyalgia [26].

Laser acupuncture is an alternative method to traditional acupuncture. Findings from an RCT involving 30 subjects with mild to moderate depression showed that the laser acupuncture group had significantly lower depression scores than did the inactive laser acupuncture group [27].

Most acupuncture clinical trials conducted in Australia are registered with the Australian Therapeutic Goods Administration and the Australian New Zealand Clinical Trial Registry. Following the introduction of the Consolidated Standards of Reporting Trials (CONSORT Statement) in 1996 [28] and its revised version in 2001 [29], clinical trials in Australia have been reported in accordance with this international standard.

Challenges in acupuncture clinical trials remain, especially in effective design and control group such as sham [30]. Researchers have identified some strategies to maintain the credibility of sham acupuncture as a control in clinical trials [31].

Against the backdrop of increasing Chinese medicine research in Australia, the Australian Journal of Acupuncture and Chinese Medicine was launched in 2006 as the first peer-reviewed journal on Chinese medicine in Australia.

\section{Conclusion}

Recent developments of acupuncture in Australia indicate that through adequate and appropriate evaluation, acupuncture is being integrated into mainstream health care in Australia.

\section{Competing interests}

The authors declare that they have no competing interests.

\section{Authors' contributions}

$\mathrm{CX}, \mathrm{AZ}, \mathrm{AY}$ and DS conceived the ideas of this article. CX, $\mathrm{AZ}, \mathrm{AY}$ and SZ collected and compiled the data, and drafted the manuscript. CX, AZ, AY, SZ and DS interpreted the data and revised the manuscript. All authors read and approved the final version of the manuscript.

\section{Acknowledgements}

The authors thank the researchers at the RMIT University and partner institutions for their research projects cited in this paper.

\section{References}

I. Loh M: Victoria as a catalyst for Western and Chinese medicine. $R$ Hist Soc Vic J 1985:38-46.

2. Xue CC, Zhang AL, Lin V, Da Costa C, Story DF: Complementary and alternative medicine use in Australia: a national population-based survey. J Altern Complement Med 2007, I3(6):643-650.

3. Easthope G, Gill GF, Beilby JJ, Tranter BK: Acupuncture in Australian general practice: patient characteristics. Med J Aust 1999, I70(6):259-262.

4. CMRBVic: The Victorian Chinese Medicine Registration Act 2000. Act No. I8/2000 Victoria, Australia. The Chinese Medicine Registration Board of Victoria 2000.

5. The Parliament of Victoria: Health Professions Registration Act 2005. Act No. 97/2005, Melbourne 2005. 
6. Xue CC, Zhang AL, Lin V, Myers R, Polus B, Story DF: Acupuncture, chiropractic and osteopathy use in Australia: a national population survey. BMC Public Health 2008, 8: 105.

7. Cohen MM, Penman S, Pirotta M, Da Costa C: The integration of complementary therapies in Australian general practice: results of a national survey. J Altern Complement Med 2005, I I(6):995-1004.

8. Gaffney L, Smith CA: Use of complementary therapies in pregnancy: the perceptions of obstetricians and midwives in South Australia. Aust N ZJ Obstet Gynaecol 2004, 44(I):24-29.

\begin{tabular}{l} 
9. History of AACMA [http://www.acupuncture.org.au/ \\
\hline
\end{tabular} history of aacma.cfm]

10. Chinese Medicine Registration Board of Victoria: Guidelines for the Approval of Courses of Study in Chinese Medicine as a Qualification for Registration. Melbourne: CMRBVic, Melbourne; 2002.

11. Xue CC, Wu Q, Zhou WY, Yang WH, Story DF: Comparison of Chinese medicine education and training in China and Australia. Ann Acad Med Singapore 2006, 35(II):775-779.

12. Xue CC, Zhou W, Zhang AL, Greenwood K, Da Costa C, Radloff A, Lin V, Story DF: Desired Chinese medicine practitioner capabilities and professional development needs: a survey of registered practitioners in Victoria, Australia. BMC Health Serv Res 2008, 8:27.

13. Victorian Government Department of Human Services: Standards of Practice for Acupuncture - Health (Infectious Diseases) Regulations 1990. Melbourne 1990.

14. Register of Chinese medicine practitioners search facility [http://www.cmrb.vic.gov.au/cgi-bin/cmweb.exe/Intro]

15. Medicare Statistical data for the June Quarter 2005 [http:// www.health.gov.au/]

16. Xue C, English R, Zhang J, Da Costa C, Li C: Effect of acupuncture in the treatment of seasonal allergic rhinitis: a randomized controlled clinical trial. Am J Chin Med 2002, 30(I): I-II.

17. Xue CCL, An X, Cheung TP, Da Costa C, Lenon GB, Thien FC, Story DF: Acupuncture for persistent allergic rhinitis: $A$ randomised, sham-controlled trial. Med J Aust 2007, | 87(6):337-34|.

18. Xue CC, Dong L, Polus B, English RA, Zheng Z, Da Costa C, Li CG, Story DF: Electroacupuncture for tension-type headache on distal acupoints only: a randomized, controlled, crossover trial. Headache 2004, 44(4):333-34I.

19. Zheng Z, Guo RJ, Helme RD, Muir A, Da Costa C, Xue CC: The effect of electroacupuncture on opioid-like medication consumption by chronic pain patients: A pilot randomized controlled clinical trial. Eur J Pain 2008, 12(5):67|-676.

20. Smith C, Crowther C, Beilby J: Acupuncture to treat nausea and vomiting in early pregnancy: a randomized controlled trial. Birth 2002, 29(I): I-9.

21. Smith C, Coyle M, Norman RJ: Influence of acupuncture stimulation on pregnancy rates for women undergoing embryo transfer. Fertil Steril 2006, 85(5): I $352-1358$.

22. Smith CA, Hay PPJ: Acupuncture for depression. Cochrane Database Syst Rev 2005:CD004046.

23. Smith CA, Crowther CA: Acupuncture for induction of labour. Cochrane Database Syst Rev 2004:CD002962.

24. Green S, Buchbinder R, Barnsley L, Hall S, White M, Smidt N, Assendelft W: Acupuncture for lateral elbow pain. Cochrane Database Syst Rev 2002:CD003527.

25. Green S, Buchbinder R, Hetrick S: Acupuncture for shoulder pain. Cochrane Database Syst Rev 2005:CD005319.

26. Deare JC, Zheng Z, Xue CC, Liu J, Shang J, Scott SW: Acupuncture for treating fibromyalgia (Protocol). Cochrane Database Syst Rev 2008:CD007070

27. Quah-Smith Jl, Tang WM, Russell J: Laser acupuncture for mild to moderate depression in a primary care setting - a randomised controlled trial. Acupunct Med 2005, 23(3): I03-III.

28. Begg C, Cho M, Eastwood S, Horton R, Moher D, Olkin I, Pitkin R, Rennie D, Schulz K, Simel D, et al.: Improving the quality of reporting of randomised controlled trials: The CONSORT statement. JAMA 1996, 276(8):637-639.

29. Moher D, Schulz KF, Altman DG, for the CORSORT Group: The CONSORT statement: revised recommendations for improving the quality of reports of parallel-group randomised trials. The Lancet 2001, 357:1191-1194.
30. Lund I, Naslund J, Lundeberg T: Minimal acupuncture is not a valid placebo control in randomised controlled trials of acupuncture: a physiologist's perspective. Chinese Medicine 2009 . 4(I): I.

31. Zaslawski C, Rogers C, Garvey M, Ryan D, Yang CX, Zhang SP: Strategies to maintain the credibility of sham acupuncture used as a control treatment in clinical trials. I Altern Complement Med 1997, 3(3):257-266.
Publish with Biomed Central and every scientist can read your work free of charge

"BioMed Central will be the most significant development for disseminating the results of biomedical research in our lifetime. "

Sir Paul Nurse, Cancer Research UK

Your research papers will be:

- available free of charge to the entire biomedical community

- peer reviewed and published immediately upon acceptance

- cited in PubMed and archived on PubMed Central

- yours - you keep the copyright 